Misiones y sus radios, una aproximación a su historia en los 100 años de la radio

Carlos A. García Da Rosa

Question/Cuestión, Vol. 2, N 66, Agosto 2020

ISSN 1669-6581

https://perio.unlp.edu.ar/ojs/index.php/question/index

IICom-FPyCS-UNLP

\title{
MISIONES Y SUS RADIOS, UNA APROXIMACIÓN A SU HISTORIA EN LOS 100 AÑOS DE LA RADIO
}

\section{MISIONES AND ITS RADIOS, AN APPROACH TO ITS HISTORY IN THE 100 YEARS OF RADIO}

\author{
Carlos A. Garcia Da Rosa \\ Magister, Docente e investigador \\ Carrera de Comunicación Social \\ Facultad de Humanidades y Ciencias Sociales \\ Universidad Nacional de Misiones \\ carlosagarciadarosa@gmail.com
}

\section{Resumen}

Un recorrido histórico desde el nacimiento de la primera emisora en Misiones hace 93 años, hasta llegar en la actualidad a más de 300. 


\title{
Palabras clave
}

Radio, Historia, Misiones

\begin{abstract}
A historical tour from the birth of the first emisora in Misiones 93 years ago, to reach today more than 300 .
\end{abstract}

\section{Keywords}

Radio, History, Misiones

\section{Introducción}

Desde los bordes de nuestro país, desde sus fronteras, desde la provincia de Misiones la que comparte más del $90 \%$ de sus fronteras con Brasil y Paraguay no sumamos a esta celebración por los 100 años de la radio. Y lo hacemos recordando a nuestra radio, rescatando su historia; misionera ella, acaba de cumplir este 19 de agosto, 93 años. Una historia que arrancó en 1925 cuando llega a Posadas, Misiones por ese entonces era Territorio Nacional, Julio Teodoro Cormillot, un ingeniero e inmigrante francés. Cormillot llega a Misiones con sus hijos Alí Andrés, Alberto Emilio y Horacio, y serán ellos los que traerán esta nueva tecnología a la región.

Don Julio, abuelo del Dr. Cormillot al que vemos siempre en la televisión, tenía experiencia en la puesta al aire de emisoras de radio. En 1923 puso en funcionamiento una radio AM en Buenos Aires y en 1924 viajó a Asunción para inaugurar la primera radio AM del Paraguay. Es allí donde se entera que, en el Norte argentino, concretamente en Misiones, no había nada, que estaba todo por hacer y decide instalar una radio comercial. Así nació un 19 DE AGOSTO 
DE 1927, siete años después de la primera transmisión radial en el mundo, RADIO MIX, una pequeña radio de 10 vatios que luego tomará el nombre de Bouquet, pero que en ese momento que visibilizará todo la actividad cultural, político, económico, social de la ciudad. Y no solo eso, sino que se constituyó en una escuela de locutores, puesto que aquellos que tuvieron una relación directa $o$ indirecta con la radio hicieron sus primeras herramientas en la sala locución de esta emisora

A principios de los años 1930, cuando se comienza a legislar para encuadrar jurídicamente y técnicamente a la radio en la Argentina, Cormillot va a trasladar su emisora a la vecina localidad de paraguaya de Encarnación, porque no podía cumplir con lo que se estipulaba en estas resoluciones y concretamente, con lo que decía el Folleto de Instrucción sobre Radiofonía de 1934 en donde se imponía condiciones muy exigentes para la explotación del servicio de radiodifusión.

Se va al Paraguay, allí el gobierno paraguayo le otorgará la licencia con el indicativo ZP3 y ZPA3, en la frecuencia de 1250 kilociclos y va a permanecer allí hasta principio de la década de 1930. No se sabe muy bien cuando sale del aire. Hay una versión que no está documentada que indica de que el gobierno paraguayo en su momento incauta los equipos para utilizarlos en la guerra del chaco paraguayo.

Al desaparecer Mix no queda ninguna radio en la región hasta principio de los años '40. Es la época, los años '40, en que la radio construye nuevos mercados para sus producciones y así comienzan a instalar filiales a lo largo y ancho de todo el país, y a transmitir en cadena. Radio Belgrano, era una de ella y fue una de las pioneras que en poner un pie en la región. El 4 de diciembre de 1941 y con la firma del presidente Higinio Morínigo, se le autoriza "la 
instalación y explotación de una estación radiofónica, por el término de 15 años", el localidad de Encarnación, no en Misiones, sino en Encarnación de una emisora que luego el 2 de junio de 1953, será transferida con todos sus derechos y obligaciones a la Compañía Paraguaya de Radiodifusión, cuyo presidente era Carlos Madelaire, un santafesino que desde muy niño vivió en Paraguay, en donde previo a su incursión en la radiofonía fue editor de varios diarios, todos ellos, clausurados posteriormente por el ex dictador Alfredo Stroessner.

Al año siguiente, el 26 de Julio de 1942, como integrante de la Red Argentina de Emisoras Splendit (RADES), saldrá al aire, pero si aquí en Posadas, LT 4 Radio Misiones.

Desde el 40, desde esta época, desde esta fecha hasta principio de los ' 60 no va a haber nuevas emisoras en el mapa mediático de la provincia. Recién el 15 de diciembre de 1963. Durante la presidencia de Arturo Illia (12-10-1963/28-061966), y el gobierno de Mario Losada en Misiones, inició su transmisión LT 13 Radio Oberá. "Abriendo picadas en el éter misionero", era su eslogan. Hugo Amable, docente y su director le asignó el rol, además, de ser una herramienta para la educación.

Al año siguiente, el 19 de junio de 1964, en Posadas sale al aire en forma definitiva en Posadas, LT 17 Radio Provincia de Misiones, una de las tres radios que actualmente posee el estado misionero. La puesta en funcionamiento de esta emisora también se conecta con el ideario de los que bregaron, en los primeros años de la década del '50, por lograr la provincialización del entonces Territorio Nacional de Misiones, hecho que se concretó en 1953 
Ese mismo año, un 11 de diciembre, en Eldorado, a unos 200 kilómetros de Posadas, sale al aire LT 18 Radio Eldorado. Fue concebida por la población del Alto Paraná "para llenar el vacío de comunicación", en una zona donde hasta ese entonces solo se sintonizaban emisoras del Paraguay y el Brasil, que por razones de orden geográfico y topográfico, principalmente, eran las que mejores llegaban a sus receptores.

Diez años después, el 20 de abril de 1972, en Iguazú inicia sus transmisiones LR 19 Radio Nacional Iguazú. Fue la primera emisora de potencia media que se instaló en la triple frontera. Contaba en ese entonces con dos equipos de $5 \mathrm{y}$ 25 kw y la finalidad era "contrarrestar la penetración" de las radios de Asunción, Curitiba, San Pablo y Foz de Iguazú, que transmitían en AM y FM con alta calidad y potencia.

Ese mismo año, el 18 de noviembre de 1972, en Posadas, sale al aire LT 85 TV Canal 12, un medio propiedad del Estado provincial que nació para "construir soberanía" en la frontera

Al año siguiente, un 1 de abril de 1973, en San Javier -con la misma intención de ser "una barrera contra la penetración de las radios esencialmente brasileñas"- sale al aire en baja potencia, pero transmitiendo en AM, LT 46 Radio San Javier. Nace por la decisión de 20 socios de la entonces Cooperativa Azucarera de San Javier como "un aporte patriótico" de los colonos que vivían en la frontera.

Tres años después, el 6 de noviembre de 1976, en Bernardo de Irigoyen comienza transmitir en AM con un equipo de 300 vatios LT 46 Radio Bernardo de Irigoyen. Es la primera emisora que se va instalar en la zona más oriental del país y la provincia, en la frontera con el Brasil. El objetivo "reafirmar los 
derechos argentinos en esta parte del país y ser una barrera a la penetración de los medios brasileños".

Y estas radios van a ser la que van a estar funcionando hasta 1985, van a ser las únicas. Y marcamos 1985 como un punto de inflexión este año porque en 1983 la Argentina recupera la democracia, recupera la vos; y van a comenzar a instalarse las primeras radios que van a transmitirán en FM, por fuera la legislación vigente, y modificarán sustancialmente el mapa de medios de la provincia; y a estas siete radios se van a sumar más de 270 en poco tiempo para hoy ser más de 300 las que están en el mapa mediático de la provincia de Misiones.

Y esta es la radio que está siendo interpelada en estos tiempos de pandemia, pero que al mismo tiempo se reivindica así misma como un instrumento más para garantizar una comunicación cada vez más democrática, pluralista, inclusiva. Desde este lugar, desde la frontera, de la provincia de Misiones, celebramos con esta pequeña historia estos 100 años de la radio en el mundo. 